${ }^{1}$ Neurólogo, Clínica Las Condes. Santiago, Chile.

Trabajo no recibió financiamiento.

El autor declara no tener conflictos de interés.

Recibido el 5 de noviembre de 2018, aceptado el 8 de enero de 2019.

Correspondencia a:

Dr. Marcelo Miranda Lo Fontecilla 441 Santiago, Chile. marcelomirandac@gmail.com

\section{La enfermedad de Johann Sebastian Bach y su mediático médico inglés}

\author{
MARCELO MIRANDA C. ${ }^{1}$
}

\section{Johann Sebastian Bach's disease and his bizarre english physician}

Johann Sebastian Bach suffered during the last year of his life of a progressive visual defect despite two operations done by a famous but quite controversial English ocular surgeon of that time. The exact diagnosis of his ocular problems is unclear but cataracts and complicated glaucoma seem the most plausible. A septic complication following the ocular surgery could have weakened Bach's health leading to his death only three months after the last intervention. In this paper diverse less known aspects of Bach's disease and life are reported.

(Rev Med Chile 2019; 147: 356-360)

Key words: Cataract; History; Music; Sepsis. es sin ohann Sebastian Bach, hijo de una familia de músicos y padre de otros tres músicos destacados, nace en Eisenach, Alemania en 1685, es sin duda uno de los más grandes músicos de la historia y para muchos el mejor. Su inmortal e ingente obra musical contrasta con la escasa y a veces poco fidedigna información disponible sobre aspectos de su vida y en especial las causas de la enfermedad que lo afectó en el último año de su vida. El objetivo de este artículo es dar a conocer estos aspectos médicos revisando la escasa información médica disponible y que es en general muy desconocida sobre este genio musical.

\section{La enfermedad y su mediático médico inglés}

Bach fue un hombre sano y robusto la mayor parte de su vida tal como se aprecia en uno de los pocos retratos auténticos pintado en 1746, 4 años antes de morir (Figura 1) ${ }^{1}$. Su único problema de salud aparente fue la presencia de dificultades visuales: siempre "fue corto de vista" según su hijo Carl Philipp Emmanuel informó a J. N. Forkel uno de los biógrafos de Bach más fidedignos ${ }^{2}$. Sus amigos lo atribuían a su increíble capacidad de trabajo pasando noches enteras estudiando, leyendo y transcribiendo música ${ }^{2,3}$. Es muy probable que haya sido miope, en base a su aspecto en el retrato con los ojos entornados y el ceño fruncido ${ }^{4-6}$; como músico ocupaba horas de trabajo diario en transcripciones y lectura, incluso desde la infancia, fue un excelente alumno y lector, obviando algunos cursos por su rendimiento sobresaliente ${ }^{5}$. La necesidad de un trabajo de cerca hace improbable un defecto de refracción que no sea miopía ${ }^{6,7}$. El año 1750 las dificultades visuales empeoran asociadas a dolor ocular por lo que su familia le sugiere consultar al famoso oculista inglés itinerante de la época el autoproclamado "Chevalier" John Taylor (Figura 2) ${ }^{8,9}$.

En marzo y abril de ese año Taylor sin un diagnóstico claro, pero pensando en la presencia de cataratas practicó 2 intervenciones de "curetaje" ocular a Bach sin ningún éxito. Taylor se caracterizaba por abandonar rápidamente el lugar donde practicaba sus intervenciones no haciéndose cargo de las complicaciones y fracasos ${ }^{8}$. Es difícil entender su aparente prestigio llegando a ser médico de cortes, y del rey inglés Jorge II, considerando la opinión de sus contemporáneos como el poeta inglés Samuel Johnson "nunca el arte del engreimiento fue desplegado a tal perfección" y "un ejemplo de cuán lejos la imprudencia e ignorancia pueden llevar" 


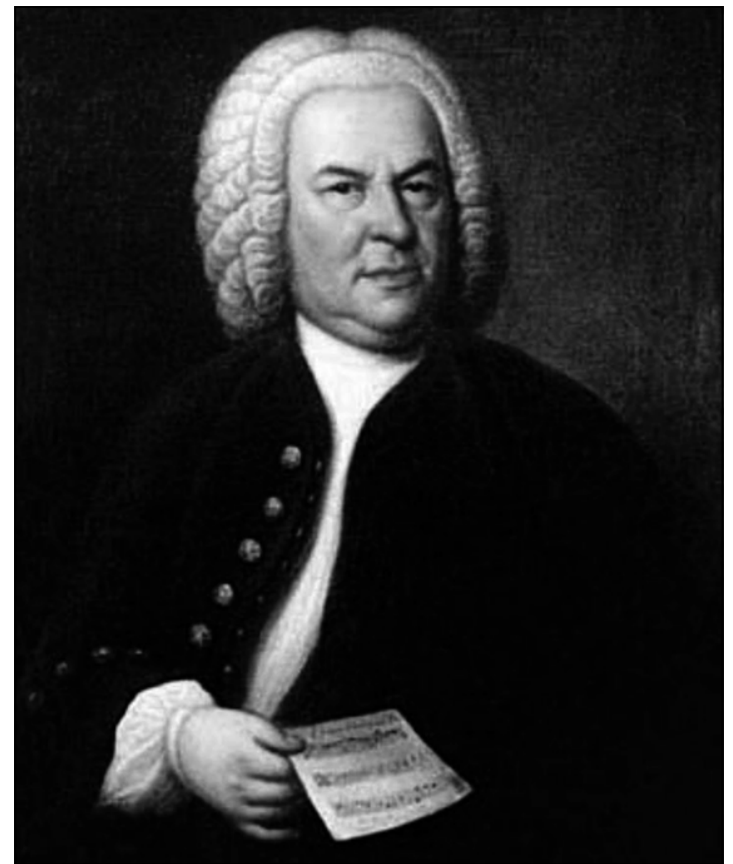

Figura 1. Retrato de Bach de 1748 uno de los pocos retratos auténticos'.
Al trasladarse en sus viajes utilizaba un carruaje completamente pintado con ojos y con una leyenda que decía "quién da visión, da vida", en sus viajes llegó hasta Rusia y Persia ${ }^{5}$. Habría muerto en París en 1772, según la leyenda, ciego ${ }^{8}$.

Sin embargo, Taylor tuvo una buena formación como cirujano, uno de sus maestros era cirujano del Papa, se sabe que Taylor describió por vez primera la cirugía del estrabismo y condiciones como el queratocono en textos dedicados a la patología ocular y en varios idiomas y constituye uno de los primeros cirujanos dedicados exclusivamente a las enfermedades oculares, incluso él mismo acuña el término "ophtalmiater", derivada del griego y que significa médico de ojos.

En la intervención de curetaje para las cataratas (Figura 3), en que Taylor se decía experto, con una aguja se perforaba la córnea, enganchando el cristalino y traccionándolo hacia abajo, bajo el nivel de la pupila, permitiendo la visión ${ }^{2,3,5,8}$. Esta antigua intervención ya estaba descrita en la antigüedad en el código de Hammurabi y aún era practicada en oriente a principios del siglo $20^{8}$.

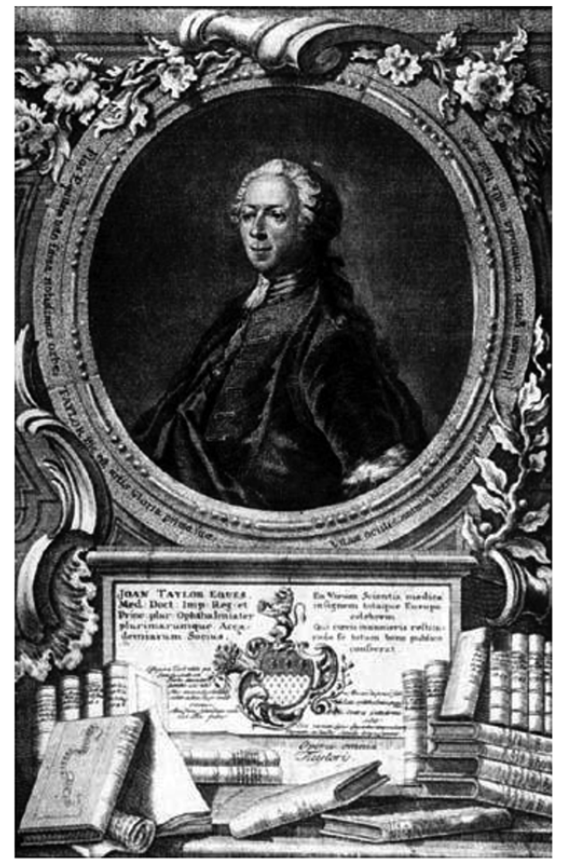

A

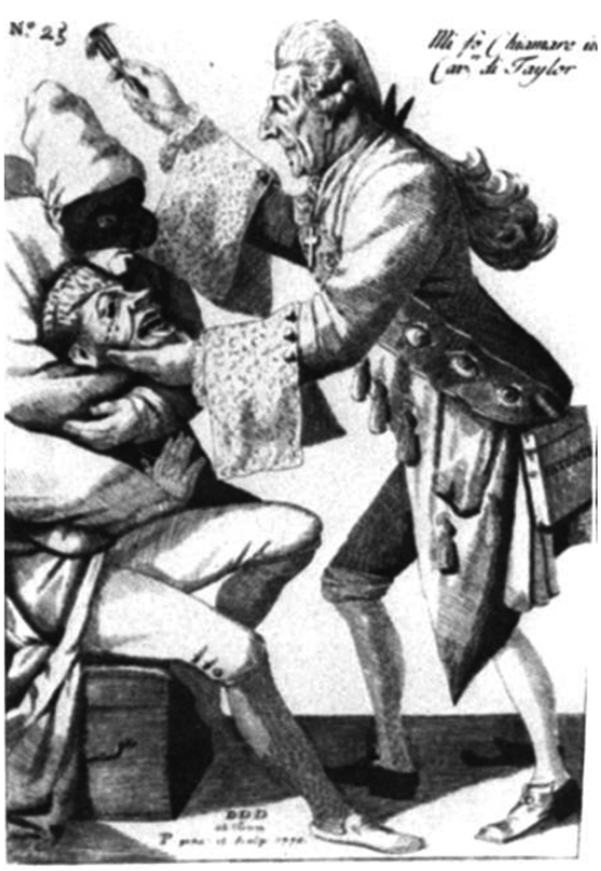

B

Figura 2. A) El oftalmólogo John Taylor quien operó a Bach en 2 ocasiones y en B) en un grabado italiano de la época en que se le caricaturiza como charlatán (dominio público, wikimedia commons). 


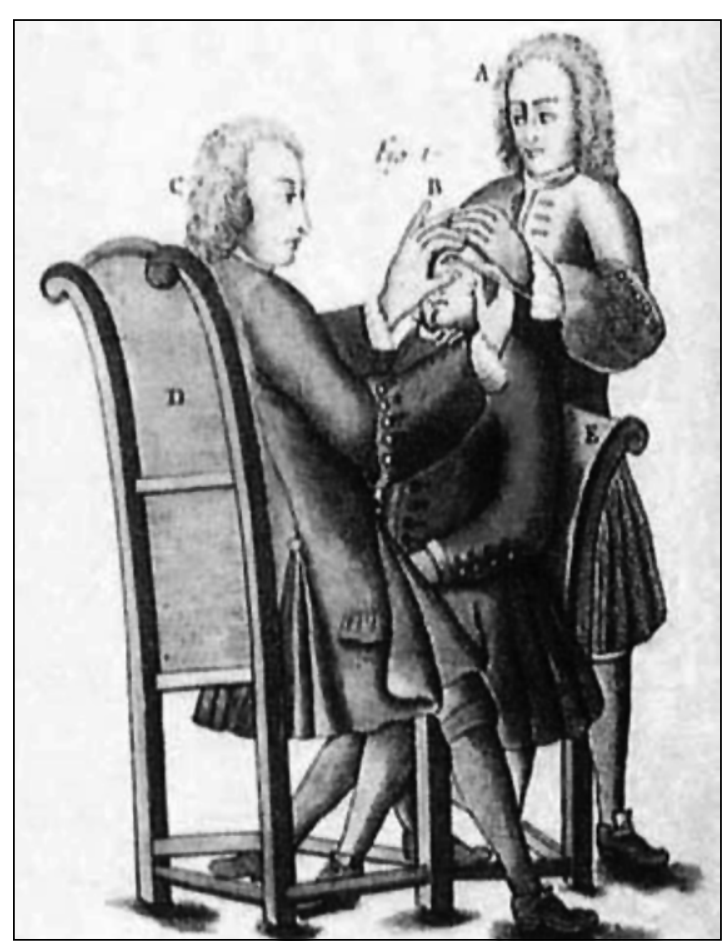

Figura 3. El procedimiento de curetaje practicado en esa época, sólo con alcohol u opio como anestésicos (dominio público, wikimedia commons).

En su autobiografía, llena de inexactitudes, Taylor se ufanaba de haber intervenido de esta manera a 2 "grandes" de la época: "para continuar, he visto una amplia variedad de animales singulares, tales como dromedarios, camellos y particularmente en Leipzig, donde un celebrado maestro de la música, ya en sus ochenta años, recibió su visión gracias a mis manos, es con este hombre que el famoso Händel se educó, y con quién pensé haber tenido el mismo éxito, teniendo todas las circunstancias a su favor, reacciones de la pupila, etc. pero el trastorno era un tipo de parálisis"8. Hay una serie de errores en estas: Bach tenía 64 años cuando recurre a Taylor, nunca Bach se reúne con Händel aún luego de 3 intentos principalmente por Bach, ambos eran contemporáneos, nacido el mismo año separados por 1 mes y vivían a sólo $85 \mathrm{Km}$ de distancia.

La vida de Bach y de Händel fue muy distinta. Bach fue un músico que podríamos llamar en la actualidad como de bajo perfil, principalmente de iglesias y pequeñas cortes en Alemania.
Aunque respetado por los músicos de la época, obtuvo escaso reconocimiento popular en vida, y después de su muerte ocurrida sólo 3 meses de la intervención de Taylor, cae en el olvido hasta ser descubierto por Mozart y músicos posteriores como Mendelssohn. Händel por otro lado, llegó a músico a pesar de la oposición de su padre, tuvo una particular adaptabilidad internacional, hablaba fluidamente 4 idiomas, y logró celebridad en vida constituyendo además un ejemplo del primer empresario musical.

\section{Los últimos días de Bach}

Como la intervención de Bach fue un fracaso, Taylor aconsejó el habitual cuidado postoperatorio que consistía en la aplicación de una mezcla de bálsamo del Perú y agua caliente aplicada directamente en los ojos, colirios de sangre de paloma, sal quemada, y azúcar pulverizada además de sangría y laxantes ${ }^{5}$. Como consecuencia de todo esto Bach quedó completamente ciego, no pudiendo completar su última obra el Arte de la Fuga. Se comunicó una transitoria recuperación de la visión, pero ha sido interpretado como un fenómeno alucinatorio, el llamado síndrome de Charles Bonnet, que describe la presencia de alucinaciones en pacientes deprivados de visión por un mecanismo de deaferentación en que la corteza occipital presenta actividad espontánea dando origen a imágenes concientemente ${ }^{3,5}$. Luego de una horas de este fenómeno alucinatorio se describe un "ataque", en esa época el término ataque o stroke en inglés puede haber indicado sólo pérdida de conciencia y no una enfermedad particular, quedando en coma y con fiebre por 10 días, falleciendo las 18:15 h del 28 de julio de $1750^{3}$. Es enterrado en el cementerio de la iglesia St Johannes de Leipzig, y la ubicación exacta de la tumba es desconocida hasta fines del siglo XIX.

\section{El descubrimiento de los restos de Bach y algunos aspectos neurobiológicos de los músicos}

En 1894 debido a la remodelación de la Iglesia de Leipzig, parte del cementerio fue removido y se aprovechó de buscar los restos de Bach. Conociendo que Bach fue enterrado en un cofre de 
encina, y que el año de su muerte sólo 12 de los 1.400 cuerpos enterrados fueron sepultados en esas urnas, se logró detectar 3 remanentes de esos 12 ataúdes el 22 de octubre de $1894^{3,9,10}$. Estos féretros fueron abiertos en presencia del profesor de anatomía de la Universidad de Leipzig, Wilhem Hiss (1831-1904), cuyo hijo homónimo alcanzará fama con posterioridad por su descripción del sistema de conducción auriculo ventricular (haz de Hiss $)^{3,9,10}$. Uno de los cofres mortuorios contenía el esqueleto completo de un "hombre mayor, no muy alto pero bien constituido". El cráneo "era fuerte y de forma característica, presentando una amplia frente, una fuerte glabela, órbitas relativamente bajas cuyas amplitudes excedían su altura y fuertes mandíbulas con una levemente protruyente mandíbula inferior"3. Fue evidente para Hiss que este cráneo era especial e inició un prolijo análisis de identificación comparando estos restos con los retratos de Bach disponibles en Leipzig pintados por JG Haussmann (Figura 1). La comparación fue claramente concordante, los retratos mostraban los rasgos fisonómicos del cráneo encontrado. No conforme comisionó a un escultor, CS Seffner, para que modelara un busto en base a una máscara obtenida del cráneo y apoyado por los retratos y el resultado fue también muy concordante ${ }^{3,10}$ (Figura 4).

El esqueleto mismo presentaba numerosas exostosis en la columna vertebral y en todas partes, y el cráneo mostraba una avanzado estado de cierre de las suturas sagital, coronal y lamboideas. Esto indicaba que el esqueleto era de un adulto

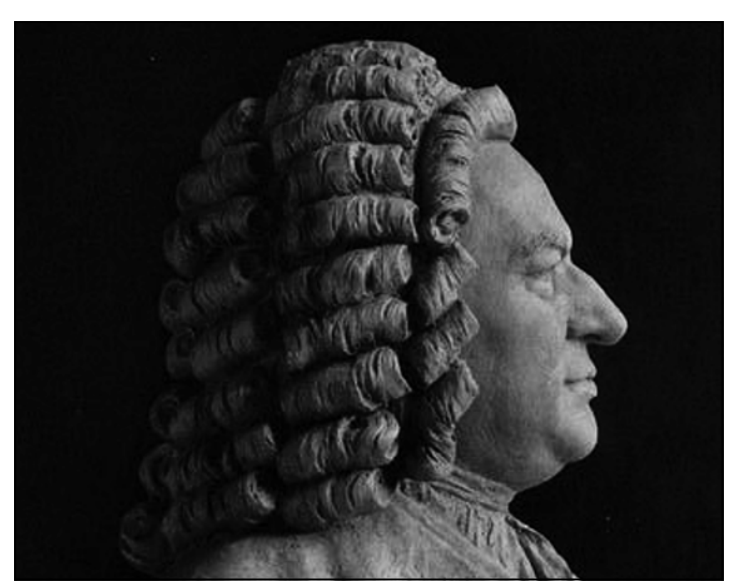

Figura 4. Busto de Bach, obra del escultor Seffner en base a los hallazgos del cráneo de Bach descubierto en 1894. mayor, lo que fue confirmado también por F. Hesse, profesor de odontología de la Universidad de Leipzig analizando la atrofia de procesos alveolares; también pudo corroborar por efectos del desgaste de la mordida que el maxilar inferior era protruyente, una característica presente en los retratos de $\mathrm{Bach}^{3,10}$. Hiss logró tener una noción por las impresiones óseas de aspectos del cerebro de Bach, se hizo asesorar por Politzer, un connotado otólogo. Si bien Hiss afirmó con mucha razón que podría ser fútil intentar dar cuenta del talento de un genio en base la estructura de sus huesos temporales, él estaba convencido que un hueso temporal bien organizado y desarrollado era indispensable para hacer un gran compositor. Fue evidente en Bach el marcado desarrollo de los huesos temporales, se confirmó por examen de sus componentes: la ventana redonda tenía un tamaño muy superior al normal 2,5 mm de diámetro vs $1,5 \mathrm{~mm}$ en normales, el extraordinario grosor y firmeza de la mastoides, particularmente en la parte cortical era notoria, también muy desarrollada estaban la incisura mastoidea, la prominencia del borde petróseo ${ }^{3,10}$. En especial las impresiones en el cráneo de los gyrus fusiforme y temporal inferior claramente sugieren un gran desarrollo de estas áreas. El gran tamaño de la primera espiral de la cóclea habla de un gran desarrollo del ganglio coclear y por ende de los centros sensoriales corticales ${ }^{3,10}$.

Investigaciones actuales, nos dan cuenta que claramente no existe un centro cerebral de la música y que las habilidades receptivas y expresivas musicales se explican por redes neuronales en ambos hemisferios ${ }^{11,12}$; en cuanto influye el componente genético en esta habilidad parece claro y el mejor ejemplo es la misma familia Bach; en una anécdota apócrifa Bach le decía a sus alumnos que "si Uds. fueran tan afanosos y perseverantes como yo lo fui en practicar tocarían rápidamente también o mejor como yo"2. Los músicos tienen ciertas características cerebrales, anatómicas como funcionales que se correlacionan con la edad a la que comenzaron su aprendizaje musical (mayor si menor de 7 años), tienen una reorganización cortical como resultado del entrenamiento musical $^{11,12}$. Si en esto hay sólo mayor plasticidad neuronal o una propiedad estructural innata no esta dilucidado ${ }^{12}$. Los cambios anatómicos más constantes en los músicos comprenden un aumento de la asimetría normal en la superficie 
del planum temporale izquierdo con respecto al derecho, el planum temporale es la porción más posterior de la corteza auditiva en la parte más superior del lóbulo temporal; también hay mayor desarrollo de la porción anterior del cuerpo calloso y mayor volumen de cerebelo en músicos hombres $^{11,12}$.

\section{Diagnóstico diferencial}

Es especulativo un diagnóstico preciso de la enfermedad que originó la muerte de Bach o sus problemas oculares ${ }^{13}$, o si ambos están relacionados pero, sin embargo, la información disponible permite formular hipótesis plausibles ${ }^{2-5}$. Un biógrafo como Baer plantea que el problema ocular de acuerdo a la edad de Bach, el inicio súbito de importante dolor ocular, la ausencia de percepción de la luz en las etapas finales orientan a un glaucoma complicado con hemorragia y que las complicaciones probablemente infecciosas lo llevaron a la muerte ${ }^{3}$. Es difícil atribuir complicaciones infecciosas como una endoftalmitis ${ }^{5}$ que evolucione en 3 meses posteriores a la operación y lleve a la muerte, lo que parece más probable que estas complicaciones hayan debilitado a Bach llevándolo a alguna complicación infecciosa de otra índole ${ }^{3}$. Terry sugiere sin clara base el diagnóstico de una nefritis intersticial crónica con retinitis ${ }^{5}$. Wolf plantea que la presencia ya de un debilitamiento de la salud en 1749 , apoyado por el hecho que se buscó un reemplazante en la capilla de la iglesia de Leipzig, el deterioro de la escritura de Bach en los últimos meses, sus mejorías transitorias harían plantear crisis isquémicas cerebrales y como factor de base una diabetes mellitus que explicaría las cataratas y un episodio final también vascular ${ }^{14}$.

\section{Conclusión}

No deja de ser irónico el hecho que el único contacto directo de Bach y Handel a pesar de los esfuerzos principalmente por parte de Bach de encontrarse, haya sido a través del hombre que los operó sin éxito, quedando ciegos ambos tanto Bach en Alemania como Händel en Inglaterra.

Si bien, como se ha descrito, no hay certeza de la causa de muerte de Bach no cabe duda del invaluable aporte de su música al patrimonio artístico de la humanidad.

\section{Referencias}

1. Towe TN. The face of Bach. En: http://www.npj.com/ thefaceofbach.

2. Forkel JN. Vida de Bach. Fondo de Cultura Económica. México. 1950. 200.

3. Baer KA. Johann Sebastian Bach in medical history. Bull Med Libr Assoc 1951; 39: 206-11.

4. Gardiner JE. La música en el Castillo del cielo: un retrato de Bach. Acantilado. Barcelona. 2015.

5. Terry JC. Bach: a biography. Oxford University Press. 1928. 264.

6. Zegers R. The eyes of Johann Sebastian Bach. Arch Ophthalmol 2005; 123: 1427-30.

7. Hepsen IF, Evereklloglu C,Bayramlar H. The effect of reading and near-work on the development of myopia in emmetropic boys; a prospective, controlled, threeyear follow-up study. Vision Res 2001; 41: 2511-20.

8. Trevor-Roper P. Chevalier Taylor-Ophthalmiater Royal (1703-1722). Documenta Ophthalmologica 1989; 71: 113-22.

9. Jackson DM. Bach, Handel and the Chevalier Taylor. Med Hist 1968; 12: 385-93.

10. Peipert JF, Roberts CS. Wilhem His Jr's finding of Johann Sebastian Bach. Am J Cardiol 1986; 57 (11): 1002.

11. Baeck E. The neural network of music. European J Neurol 2002; 9: 449-56.

12. Miranda M, Hazard S, Miranda P. La música como una herramienta terapéutica en medicina. Rev Chil Neuro-Psiquiat 2017; 55: 266-77.

13. Grzybowski A. John Taylor and Johann Sebastian Bachmore information still needed. Acta Ophthalmol 2013; 91 (3): 250-2.

14. Wolff C. Bach: the learned musician. WWNorton \& Company, New York, 2001; 442. 